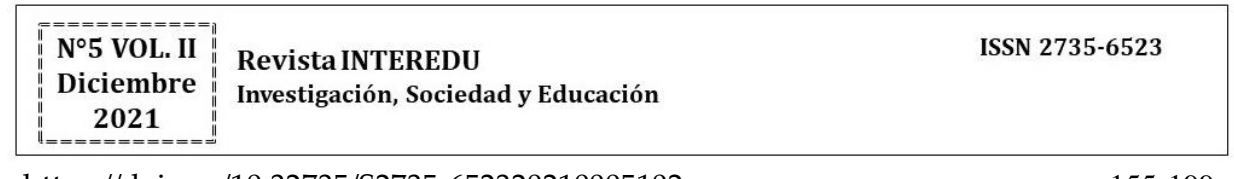

https://doi.org/10.32735/S2735-652320210005102

155-199

\title{
Prácticas reflexivas en Procesos evaluativos de Profesores DE EDUCACIÓN PRIMARIa
}

Reflective practices in evaluative processes of elementary school teachers

\author{
RAQUEL HERMOSILLA- MÉNDEZ. ${ }^{1}$ \\ Universidad Católica de la Santísima Concepción, Chile \\ rhermosilla@magisteredu.ucsc.cl \\ https://orcid.org/0000-0001-6365-0666 \\ PILAR JARA-COATT. ${ }^{2}$ \\ Universidad Católica de la Santísima Concepción, Chile \\ pilarjara@ucsc.cl \\ https://orcid.org/0000-0002-9975-8713
}

\section{RESUMEN}

El propósito del estudio es analizar los factores que obstaculizan y facilitan la reflexión y los elementos evaluativos sobre los que reflexionan los profesores de educación básica, respecto de las prácticas reflexivas de evaluación de aprendizajes realizados por docentes. Se desarrolló bajo un paradigma interpretativo, metodología cualitativa y estudio de caso, utilizando la entrevista semi-estructurada a partir de un guion de preguntas para realizar un análisis de contenido, estableciendo categorías y subcategorías. Dentro de los resultados, se destacan la falta de instancias formales y colectivas entre docentes para la

1 Profesora de Educación General Básica. Diplomada en Ciencias de la Educación, mención Evaluación de los aprendizajes, de la Universidad Católica de la Santísima Concepción, Chile. Postítulo en Comprensión del Medio Natural para segundo ciclo básico. UCSC.

${ }^{2}$ Magister en Ciencias de la Educación, mención Evaluación Curricular, de la Universidad Católica de la Santísima Concepción, Chile.

Recibido: 5 de abril de 2021

Aceptado: 24 de mayo de 2021 
reflexión evaluativa. A pesar de ello, los participantes del estudio manifestaron reflexionar de manera autónoma y en oportunidades en lo cotidiano de sus prácticas con pares. Además, reflexionaron de manera focalizada sobre los instrumentos de evaluación. Como conclusión, se hace necesario implementar prácticas reflexivas en los procesos de evaluación de aprendizajes y conocer cómo las unidades técnico-pedagógicas acompañan a los docentes en sus procesos reflexivos, no solo en base al análisis de resultados sino en los distintos ámbitos de la evaluación. La principal limitación fue la poca literatura basada en la reflexión de los procesos evaluativos, como también la falta de estudios empíricos en esta área.

Palabras clave: Educación primaria, evaluación del estudiante; práctica pedagógica; reflexión docente.

\section{ABSTRACT}

The purpose of this study is to learn from those factors that affect the pedagogical practices of Physical Education primary teachers, from the reflective practices to evaluation strategies, over the expected learning, in the frame of the curricular framework. This research was carried out under a qualitative model and an case-study interpretive paradigm, in which semi-structured interviews were applied from a set of key questions which allowed us to categorize and classify the information collected. The analysis of these data revealed that there is lack of collective and formal spaces for the pedagogical reflection, which would be balanced thanks to the individual and autonomous pedagogical reflection, that finally occured in informal spaces. The pedagogical experiences of these teachers allow us to conclude that the implementation of reflective practices in the processes of learning evaluation is absolutely necessary, as it is the pedagogical assessment that the Technical-Pedagogical Unit should provide to teachers, especially in the application of effective evaluation strategies.

Key words: Primary education; learning; evaluation; pedagogical practices; teacher reflection.

156 | INTEREDU № 5 VOL. II (DiCIEMBRE 2021) PÁGs. 155-199. ISSN: 2735-6523 
Prácticas reflexivas en procesos evaluativos de profesores de enseñanza básica

\section{INTRODUCCIÓN}

La evaluación es una práctica inherente al proceso de enseñanza aprendizaje. El Ministerio de Educación (Mineduc) entrega diferentes lineamientos que orientan la práctica docente en evaluación de aprendizajes, tales como las orientaciones para la evaluación formativa, el Decreto de Evaluación, Calificación y Promoción Escolar, dentro del cual se establece que la evaluación se debe utilizar para comunicar y reflexionar sobre el aprendizaje de manera consciente y sistemática, reformulándola para contribuir y garantizar una educación de calidad (Mineduc, 2018). A través del Marco para la Buena Enseñanza, Mineduc atribuye al docente la obligación profesional de reflexión de sus prácticas no solo de aprendizaje, sino también evaluativas, siendo una de sus responsabilidades profesionales la reflexión consciente y sistemática sobre su práctica y reformularla, contribuyendo así a garantizar una educación de calidad para todos sus estudiantes (Mineduc, 2008).

Para categorizar el desempeño en el ámbito de la reflexión pedagógica, en la evaluación de desempeño docente se señala el indicador "Atribución de los resultados de aprendizaje obtenidos por los alumnos en la evaluación”. En este indicador que tributa a la reflexión de la evaluación se refiere a la capacidad del docente para analizar los resultados obtenidos por los alumnos en la evaluación aplicada al término de la unidad, identificando los aspectos logrados y no logrados y los factores que incidieron en ello, incluyendo como principal factor explicativo su propio actuar como docente. Solo un 30\% de los evaluados el año 2019 obtiene un resultado en nivel competente o destacado, vislumbrando este ámbito como una de las debilidades de los docentes chilenos (Mineduc, 2020).

En cuanto al proceso de reflexión docente Muñoz et al., (2016) concluyen que este proceso es un factor que condiciona la mejora para las INTEREDU № 5 VOL. II (DiCIEMBRE 2021) PÁGs.155-199. ISSN: 2735-6523| 157 
prácticas de evaluación, siendo necesaria para el aprendizaje de los estudiantes. La evaluación entrega una gran variedad de elementos necesarios al docente, el cual, a través de procesos reflexivos, logra identificar qué elementos de sus prácticas deben ser reformulados para la mejora. Por ello se busca impulsar una mirada de la evaluación que fomente la reflexión permanente del quehacer docente (Torres, 2017).

La reflexión en torno a los agentes de evaluación permite obtener información sobre la práctica docente. Rodríguez (2019) expone que los espacios de diálogo consensuados permiten identificar la necesidad que los docentes prioricen la evaluación cualitativa sobre la cuantitativa, pero no dan los tiempos para hacerlo.

La evaluación de aprendizajes se plantea como una oportunidad para la reflexión de la práctica pedagógica, desde donde se proyecta como objetivo general de esta investigación: Describir los aspectos que determinan las prácticas reflexivas en los procesos evaluativos desarrollados por profesores de enseñanza básica de un colegio particular subvencionado de la comuna de San Pedro de la Paz, siendo los objetivos específicos: caracterizar los aspectos que favorecen o dificultan realizar prácticas reflexivas en evaluación, e identificar los componentes evaluativos sobre los cuales los profesores realizan prácticas reflexivas.

\section{EVALUACIÓN DE APRENDIZAJE}

Entendemos la evaluación de aprendizajes como un proceso sistemático de recogida de información continua, que permite tomar decisiones adecuadas para continuar la actividad educativa, siendo una actividad de reflexión sobre la enseñanza y un proceso de obtención de la información que permite emitir juicios y toma de decisiones (Santos, 2014; Castillo y Cabrerizo, 2010). 
Conocer con qué finalidad se evalúa es crucial, pues la evaluación puede darse en diferentes momentos de los procesos de enseñanzaaprendizaje y, también, puede servir para la toma de decisiones (Gallardo et al., 2012). La información obtenida a través de las instancias evaluativas nos permite identificar tres grandes propósitos por los cuales los docentes evalúan a sus estudiantes: para la toma de decisiones pedagógicas que faciliten la mejora del aprendizaje, más que etiquetarlos en un nivel u otro (Martínez, 2016). Por ende, es importante su utilidad en la toma de decisiones para elevar la calidad del proceso de enseñanza-aprendizaje (Jordán et al., 2017), para el logro de objetivos que se deben alcanzar, es decir, corroborar el logro de aprendizajes (Brookhart, 2009), así como para la mejora continua de su labor docente (Chuappuis y Stiggins, 2002).

Un aspecto relevante dentro del proceso de evaluación de aprendizajes es la retroalimentación, por consiguiente, decir que sin retroalimentación no existe evaluación no es una exageración (Martínez, 2016). Un proceso de retroalimentación efectiva no debe darse solo del docente al estudiante, si no entre compañeros, como auto retroalimentación, o la vista como más valiosa por algunos, la retroalimentación del estudiante al docente (Clarke, 2014).

\section{COMPONENTES DE LA EVALUACIÓN DE APRENDIZAJES}

Para evaluar los aprendizajes se debe especificar y concretar el tipo de aprendizajes que se quiere promover, así los saberes a evaluar, pues estos son las formas de exteriorización de los aprendizajes internos (Yurén et al., 2005). Se debe tener claridad sobre cuáles evaluar: centrado en la atención y memoria, preparación para la realización de tareas y contribución de la educación al desarrollo global de cada persona (Delors, 1996).

Dependiendo del sujeto evaluador es posible considerar la autoevaluación, la coevaluación y la heteroevaluación. La autoevaluación 
corresponde a aquella en que el estudiante evalúa su propio desempeño (Martínez, 2016). Esta solo sucederá si el docente ayuda al estudiante a desarrollar la habilidad para hacerlo, lo cual requiere de tiempo y práctica sistemática y que no se realice de manera aislada (Moreno, 2016). Importante complemento de la autoevaluación es la coevaluación, evaluación entre pares (Casanova, 2007). Así, el profesor puede estar libre para observar y reflexionar sobre lo que está sucediendo (Martínez, 2016). Cuando se realiza la evaluación entre personas de diferentes niveles nos referimos a la heteroevaluación. El profesor es el encargado de medir el aprendizaje del alumno, como también el estudiante puede realizar la evaluación considerando el quehacer del docente (Martínez, 2016). Finalmente, la meta evaluación se refiere a la evaluación aplicada a una evaluación, siendo esta una estrategia basada en la reflexión para la mejora constante durante todo el proceso de enseñanza aprendizaje (Marcipar y Luciani, 1974).

En función al momento de la evaluación, es decir, en un proceso continuo o al término de una unidad, se distinguen tres tipos (Ahumada, 2001). En primer lugar la evaluación inicial, la cual permite diseñar estrategias y acomodar la práctica a la realidad del grupo (Castillo y Cabrerizo, 2010), analizar la situación del evaluando antes dar inicio del proceso (Sanmartí, 2007), así como comprobar el grado de alcance de objetivos previos necesarios para lograr los nuevos objetivos, teniendo un carácter diagnóstico que permita tomar decisiones pertinentes para orientar el proceso antes de su inicio (Pimienta, 2008). Por su parte, la evaluación de proceso es de carácter continuo, realizada principalmente a través de procedimientos informales y según las capacidades diagnósticas de los profesores, permitiendo identificar el nivel del estudiante para adaptar la enseñanza a favor de las metas de aprendizaje que se desea alcanzar. Los estudiantes tienen un rol activo con el docente, 160 | INTEREDU № 5 Vol. II (DiCIEMBRE 2021) PÁGs. 155-199. ISSN: 2735-6523 
comparten metas y comprenden cómo van progresando (Moreno, 2016). Consecuente con esto, Casanova (2007) señala que la rigurosidad de esta evaluación conlleva a mejorar el proceso de enseñanza, ya que favorece la recogida sistemática de información, lo que permite la toma de decisiones inmediatas a la resolución de las dificultades que van presentando los estudiantes. La evaluación final permite que se comprueben los resultados obtenidos, aunque no por ello debe tener funcionalidad sumativa exclusivamente (Castro et al., 2006). Tiene como propósito determinar niveles de rendimiento, posee un carácter retrospectivo, sanciona lo que ha ocurrido, viéndolo desde el proceso final (Gimeno, 1997).

Considerando los medios, procedimientos (técnicas) e instrumentos de evaluación, estos dependen del sentido y la forma que se le dé a la misma (Rodríguez e Ibarra, 2011), es fundamental que el docente elija coherentemente estos elementos esenciales para cumplir el propósito evaluativo. Los medios para evaluar consisten en pruebas o evidencias que sirven para recabar información sobre el objeto a evaluar. Estas evidencias, productos o actuaciones realizadas por los estudiantes son los medios que nos informan sobre los resultados de aprendizaje, pues se utilizan para realizar las valoraciones correspondientes. Entre los medios de evaluación están las presentaciones orales, los trabajos escritos, la reseña de un libro, la realización de una actividad, entre otros.

Respecto de los procedimientos, los más conocidos son la observación -la información es obtenida por el profesor a través de escuchar y ver el desempeño del estudiante-, prueba o encuesta -la información sobre el desempeño del alumno es obtenida mediante tareas en las que el profesor le pregunta sobre datos o situaciones concretas e informe o análisis de producciones- (Martínez, 2016).

Los instrumentos de evaluación son insumos reales y concretos que se utilizan para sistematizar los juicios realizados sobre diversas áreas 
(Rodríguez e Ibarra, 2011). Algunos ejemplos son: las listas de control, las escalas de estimación, las rúbricas, las escalas de diferencial semántico, las matrices de decisión o incluso instrumentos mixtos donde se mezclan más de uno. La falta de relación entre el medio, el procedimiento y el instrumento puede invalidar la evaluación (Martínez, 2016).

\section{REFLEXIÓN PRÁCTICA EVALUATIVA}

La reflexión docente se realiza sobre los elementos que involucran las prácticas, tales como el currículo, la planificación, las actividades, la evaluación, el contexto de los estudiantes, sus intereses y necesidades, expectativas de la escuela, las propias expectativas, entre otros. Estos elementos generan la necesidad del acto reflexivo, cuya naturaleza se encuentra en todos estos. Usualmente no pueden ser abarcados en su totalidad durante la reflexión, ya que la mayoría se ven involucrados en forma implícita, por lo cual, al momento de encontrar la solución a alguna problemática en particular, estos también se encuentran beneficiados en este accionar, cumpliéndose así el propósito de la práctica reflexiva. Las prácticas de evaluación de aprendizajes constituye uno de los campos del quehacer docente más complejos de analizar, pues posee un fuerte componente de decisión individual influenciado por prácticas tradicionales que al momento no han sido lo suficientemente analizadas. La autonomía profesional y confianza en las prácticas son cuestionadas cuando se intenta conocer cómo se realizan los procesos evaluativos. Se suelen dar a conocer los instrumentos utilizados, pero pocas veces los criterios que llevan a tomar decisiones acerca de la calificación o promoción. Giovanniello (2017) plantea que los docentes no han tenido la oportunidad de problematizar colectivamente la evaluación y dejan la construcción de modelos evaluativos solo a cargo de su experiencia 162 | INTEREDU № 5 VOL. II (DiCIEMBRE 2021) PÁGs. 155-199. ISSN: 2735-6523 
individual. Hernández et al. (2018) declaran que los colegios reconocen la importancia de mejorar los procesos evaluativos e implementan acciones limitadas a capacitaciones metodológicas, las cuales no logran profundizar en aspectos fundamentales de la evaluación. En consecuencia, sucede lo que hacen que muchas iniciativas y actividades destinadas a la mejora del profesorado y en particular a la evaluación: no cumplen su propósito.

Ahora bien, la evaluación es un permanente proceso reflexivo apoyado en evidencias de diverso tipo (Costamagna, 2008). Por su parte, el Mineduc (2018), desde la reforma educativa de los años noventa ha estado orientando a través de diversos instrumentos la reflexión sobre las prácticas de evaluación de los profesores en el aula, asumiendo que debe estar correlacionada con el foco de la mejora de los aprendizajes que es esencial en el acto educativo (Vargas, 1998). Es preciso que los profesores consideren los resultados de la evaluación para reorientar y transformar sus prácticas en busca de mejoras en los resultados de aprendizaje de los estudiantes. En relación a esta idea el artículo 18 del Decreto 67/2018 busca fomentar la reflexión a partir de la evaluación (Mineduc, 2018).

Entre los procesos reflexivos está inherente la reflexión sobre las prácticas evaluativas utilizadas por los docentes. Desde este aspecto Muñoz et al. (2016) estudiaron el proceso de reflexión docente para mejorar las prácticas de evaluación de aprendizaje. En este trabajo se concluyó que es necesario dar instancias reflexivas que permitan visualizar la evaluación como una herramienta para la mejora del aprendizaje, siendo necesario reflexionar sobre el significado y uso que se le da a la evaluación de aprendizajes. Ello, pues el profesorado podría tener dominio en la elaboración de instrumentos y aplicación de procedimientos de evaluación, pero no utilizarlos con un sentido formativo. Por otra parte, Rodríguez (2019) expone que los espacios de 
diálogo consensuados permiten identificar que existe la necesidad que los docentes prioricen la evaluación cualitativa sobre la evaluación cuantitativa. Los docentes reconocen que en los encuentros de saberes se logra reflexionar sobre las prácticas evaluativas aplicadas y se exponen ideas para su transformación, razón que justifica la necesidad de generar espacios de discusión colectiva. A su vez, Torres et al. (2020) concluyeron que los docentes poseen juicios, interpretaciones y supuestos que no se examinan, disciernen o analizan, principalmente porque los instrumentos de autoevaluación y coevaluación que se utilizan en la institución no favorecen estos procesos de reflexión. Asimismo, porque no existen espacios dispuestos para tal efecto, planteándose como alternativa la conformación de pares académicos para estudiar analítica y críticamente cuestiones de orden teórico y técnico respecto de la docencia, para la toma de decisiones certeras y la adecuada calidad educativa. Las reuniones de Consejo Técnico Escolar propiciarían el análisis de las prácticas de evaluación de aprendizajes a partir del trabajo reflexivo colaborativo, lo cual es visto por los profesores como áreas de oportunidad para mejorar la práctica mediante el trabajo colaborativo, fortaleciendo una relación de apertura entre ellos y reflexionando sobre sus prácticas evaluativas. Hernández-Nodarse (2017) declara que los docentes buscan que sus prácticas de evaluación sean formativas, efectivas y pertinentes, pero no siempre las instituciones educativas les entregan las orientaciones y/o capacitaciones requeridas para ello.

Schön (1992) desarrolla la noción de práctica reflexiva como un conocimiento que se forja a partir de la reflexión en y sobre la acción. Al relacionar esta noción a la experiencia de los profesores, se podría afirmar que este conocimiento práctico reconfigura el marco de actuación de los profesores y mejora su práctica docente. Dewey (1998), habla de la necesidad de tener un pensamiento reflexivo sobre lo que estamos 164 | INTEREDU № 5 VoL. II (DiCIEMBRE 2021) PÁGs. 155-199. ISSN: 2735-6523 
haciendo y las consecuencias de nuestro actuar. El pensar reflexivo es aquel esfuerzo que tiene una intencionalidad clara, que busca conexiones entre lo que los docentes hacen y las consecuencias de sus prácticas pedagógicas. Por su parte, Anijovich y Capelletti (2018) plantean que la formación en la práctica reflexiva, en base al análisis de la propia experiencia, favorece que los maestros puedan dirigir su propio desarrollo profesional siendo crucial incorporar esta práctica. También develan que entre los factores que dificultan el proceso de reflexión está la manera en que se organiza el trabajo del docente, lo cual no permite abrir instancias colectivas de análisis y reflexión. Asimismo la falta de tiempo para el trabajo colectivo, quienes al trabajar en aislamiento se sienten solos y desbordados ante las problemáticas. Es relevante mencionar que la práctica reflexiva es una actividad aprendida que requiere un análisis metódico, regular, instrumentado, sereno y efectivo, y que esta solo se adquiere con un entrenamiento voluntario e intensivo (Domingo y Gómez, 2014). La práctica reflexiva es responsabilidad de cada uno, pero también es vital que dentro del ámbito de la gestión se den los espacios para que esta se pueda desarrollar de manera colectiva, cooperativa y planificada, con el fin de generar cambios en las prácticas docentes e instalar una cultura de la mejora continua, específicamente en el ámbito de la evaluación que es el motor del aprendizaje (Sanmartí, 2007).

\section{METODOLOGÍA}

\section{PARADIGMA Y TIPO DE METODOLOGÍA}

El paradigma de la investigación es interpretativo, ya que no se realizó un control directo de las categorías, esto debido a que sus manifestaciones ya han ocurrido (Buendía et al., 1998). Se observó el fenómeno tal y como se desarrolla en su contexto natural para después analizarlo, es decir, simplemente al explicitar los significados subjetivos 
asignados por los actores a sus acciones, llegando a explicar por qué dichas acciones tienen sentido para los sujetos que las emprenden (Carr y Kemmis, 1988). El enfoque de este estudio es cualitativo, considerando un amplio sentido de la investigación que produce datos descriptivos: las palabras de las personas habladas o escritas y lo que ellos hacen y su sentido, permitiendo una rigurosa descripción contextual de las situaciones a través de la recogida sistemática de datos para llegar al análisis descriptivo (Pérez, 2008). Para este estudio además, se consideró el método fenomenológico, (Fuster, 2019). Ello, pues se focalizó en describir los aspectos que determinan las prácticas reflexivas en los procesos evaluativos desarrollados por los participantes, quienes eran profesores de educación básica, así como en comprender cómo se realiza la reflexión docente de procesos evaluativos de aprendizajes utilizados por profesores de un colegio particular subvencionado, dando prioridad a los aportes de los docentes frente a sus prácticas reflexivas relacionadas a la evaluación, desde lo que declaran y a partir de la reflexión de la experiencia vivida.

\section{SELECCIÓN DE CASOS}

Se utilizó un estudio de caso que consiste en una estrategia de investigación dirigida a comprender las dinámicas presentes en contextos singulares (Martínez, 2006). Esto con el propósito de acceder a la comprensión de un fenómeno tal como lo ven los sujetos de estudio. En la investigación se abordó un estudio de caso único, dado que no se han presentado antecedentes empíricos que tributen a la reflexión de los procesos evaluativos. De este modo se buscó contribuir a la generación de nuevo conocimiento, lo que se reafirma con lo planteado por Neiman y Quaranta (2006), quienes plantean que un estudio de caso único prioriza 166 | INTEREDU № 5 VOL. II (DiCIEMBRE 2021) PÁGS. 155-199. ISSN: 2735-6523 
el conocimiento profundo del caso con sus particularidades por sobre la generalización de los resultados, utilizándose para estudiar una situación particular en profundidad, la cual es significativa en su contexto.

El estudio se focalizó en un grupo de seis profesores de educación básica de la comuna de San Pedro de la Paz. La selección de los sujetos de investigación se realizó de modo intencionado que, según Ruiz (2003), pretende comprender los casos seleccionados sin generalizar los resultados. Además, es a la vez una muestra homogénea que posee un mismo perfil, características, o tienen rasgos similares en base a experiencias comunes. En este caso, los participantes son profesores de educación básica que impartían clases en un establecimiento particular subvencionado de la comuna de San Pedro de la Paz, todos con más de 10 años de experiencia (Hernández et al., 2014) (ver Tabla 1).

Tabla 1. Participantes y siglas.

Docente

Sigla

Profesora de Enseñanza básica con mención en educación PBMM1 matemática, con 15 años de experiencia.

Profesora de Enseñanza Básica con mención en Lenguaje y PBML comunicación, con 10 años de experiencia.

Profesora de Enseñanza Básica con mención en Educación Física, PBMEF con 15 años de experiencia.

Profesora de Enseñanza Básica con mención en inglés, con 15 años PBMI de experiencia.

Profesora de Enseñanza Básica con mención en educación PBMM2 matemática, con 10 años de experiencia.

Profesora de Educación General Básica, con 20 años de experiencia. $\quad$ PB Fuente: Elaboración propia. 


\section{TÉCNICA E INSTRUMENTO PARA RECOGIDA DE INFORMACIÓN}

Se utilizó la entrevista semi-estructurada, dado que permite obtener representaciones de carácter individual en relación al fenómeno investigado, logrando la recopilación de opiniones o de conocimientos de varios entrevistados para comprender el fenómeno de estudio desde la realidad de la persona entrevistada (Álvarez-Gayou, 2014). El instrumento es una guía de preguntas abiertas, las que en la investigación cualitativa son susceptibles de codificar (Álvarez-Gayou, 2014). Se realizaron las entrevistas individuales a seis profesores de educación básica. Estas entrevistas se llevaron a cabo a partir de un guion de preguntas elaboradas a partir de la revisión bibliográfica, y validadas por tres docentes expertos en educación. Los aportes realizados por los expertos permitieron hacer ajustes al instrumento antes de su aplicación.

\section{ANÁLISIS DE LA INFORMACIÓN}

Se utilizó como técnica el análisis de contenido, esta permite analizar las entrevistas que han sido aplicadas, grabadas y transcritas (Pérez, 2011), cumpliendo con el criterio de credibilidad (Vasilachis, 2004); es decir, los participantes pudieron revisar la transcripción de las entrevistas. Se optó por este tipo de análisis porque permite indagar de manera exhaustiva el lenguaje utilizado por los participantes (Hernández et al., 2014). Se realizó la confección de matrices de análisis de contenido por categorías asignándoles una denominación global, siendo estas categorías pertinentes y ajustadas a los objetivos e interrogante de la investigación (Ballestín y Fábregues, 2018), teniendo en consideración que pueden surgir otras en el desarrollo de la investigación (Araneda et al., 2008). Frente a esto, se analizaron de manera reiterada los códigos establecidos, agrupándolos en categorías y reagrupando en sub168 | INTEREDU № 5 VOL. II (DicIEMBRE 2021) PÁGs. 155-199. ISSN: 2735-6523 
categorías, lo que permitió reducir el contenido para finalmente extraer o verificar conclusiones (Bisquerra et al., 2014).

Para una descripción detallada de las prácticas reflexivas de los procesos evaluativos, a priori se definieron algunas categorías de análisis y se reservó para la etapa de reducción de los datos la eventual configuración de categorías emergentes. Así, las categorías apriorísticas para esta investigación fueron: propósito de la evaluación, tipos de saberes a evaluar, agentes de la evaluación, momentos de la evaluación, retroalimentación y procedimiento de evaluación. De manera transversal para cada temática se desarrolló el tema de reflexión docente.

Tabla 2. Categorías apriorísticas.

- Categoría apriorísticas

- Propósito de la evaluación

- Tipos de saberes a evaluar

- Agentes de la evaluación

- Procedimientos de evaluación

- Momentos de la evaluación

- Retroalimentación

Fuente: Elaboración propia

Tabla 3. Categorías, sub categorías de análisis.

\begin{tabular}{ll} 
Categoría & Sub-categoría \\
\hline Propósito de la evaluación & Toma de decisiones \\
\cline { 2 - 2 } & Logro de objetivos \\
\cline { 2 - 2 } & Retroalimentación \\
\hline Tipos de saberes a evaluar & Conocer \\
\cline { 2 - 2 } & Saber hacer \\
\cline { 2 - 2 } Agentes de la evaluación & Ser \\
\cline { 2 - 2 } & Autoevaluación \\
\hline
\end{tabular}




\begin{tabular}{ll} 
& Coevaluación \\
\cline { 2 - 2 } & Metaevaluación \\
\hline Momentos de la evaluación & Inicial \\
\cline { 2 - 2 } & Proceso \\
\cline { 2 - 2 } Procedimientos de evaluación & Final \\
\hline Práctica reflexiva & Reflexión práctica evaluativa \\
\cline { 2 - 2 } & Obstaculizadores \\
\cline { 2 - 2 } & Características práctica reflexiva \\
\hline
\end{tabular}

Fuente: Elaboración propia

\section{RESULTADOS}

A continuación, se presentan los resultados considerando las categorías, sub-categorías, citas y códigos levantados.

Tabla 5. Categoría: Propósito de la evaluación.

\begin{tabular}{|c|c|c|}
\hline Sub-categoría & Cita textual & Código \\
\hline \multirow[t]{2}{*}{$\begin{array}{l}\text { Toma } \\
\text { decisiones }\end{array}$} & $\begin{array}{l}\text { Me doy cuenta, veo las debilidades de los } \\
\text { chiquillos, en que están débiles para } \\
\text { enfrentar lo que se viene (PBMM1). }\end{array}$ & $\begin{array}{l}\text { Identificación } \\
\text { debilidades }\end{array}$ \\
\hline & $\begin{array}{l}\text { Siempre tratando de reforzar contenidos } \\
\text { que los chiquillos van a tener que utilizar } \\
\text { para afrontar lo que sigue (PBMM1). }\end{array}$ & $\begin{array}{l}\text { Repaso de } \\
\text { contenido. }\end{array}$ \\
\hline \multirow[t]{2}{*}{ Logro de objetivos } & $\begin{array}{l}\text { El objetivo de evaluar es para ver si logré los } \\
\text { objetivos con los niños (PBMEF). }\end{array}$ & $\begin{array}{l}\text { Cumplimiento } \\
\text { de objetivos }\end{array}$ \\
\hline & $\begin{array}{l}\text { Dar más tiempo, reforzar a los niños que les } \\
\text { fue mal y así finalmente logran los objetivos } \\
\text { de la evaluación (PBMEF). }\end{array}$ & $\begin{array}{l}\text { Reforzamiento } \\
\text { objetivos }\end{array}$ \\
\hline Retroalimentación & $\begin{array}{l}\text { Se van dando cuenta y vemos el porcentaje } \\
\text { de aciertos y los errores que van cometiendo, }\end{array}$ & $\begin{array}{l}\text { Aciertos } \\
\text { errores }\end{array}$ \\
\hline
\end{tabular}

170 | INTEREDU № 5 VOL. II (DicIEMBRE 2021) PÁGs. 155-199. ISSN: 2735-6523 
Prácticas reflexivas en procesos evaluativos de profesores de enseñanza básica

\begin{tabular}{l} 
entonces yo inmediatamente voy ahí \\
retroalimentado los errores (PBMM1). \\
Oriento para que vayan respondiendo entre Refuerzo \\
sí, colaborando con sus compañeros, asi entre pares. \\
realizo retroalimentación (PBMM1). \\
\hline Reforzamos, retroalimentamos... en las Búsqueda de \\
próximas evaluaciones les va mejor mejoras \\
$(P B M L)$.
\end{tabular}

Fuente: Elaboración propia

Tabla 6. Categoría: Reflexión práctica docente.

\begin{tabular}{lll} 
Sub-categoría & Cita textual & Código \\
\hline Reflexión práctica & Preocuparme que esté bien hecho, bien & Construcción \\
evaluativa & elaborada la pregunta, que no tenga de \\
& distractores... que sea un instrumento instrumentos. \\
& efectivo... (PBMM1). & \\
\hline Busco la mejor manera de evaluarlos en base & Características \\
& a sus características... (PBMEF). & estudiantes. \\
\hline & Las instancias las hace uno, por ejemplo, me & Reflexión para \\
& va mal en una evaluación con un grupo, ahí & volver \\
& lo comento con profesora jefe, con & evaluar \\
& coordinadora, UTP, para replantear, & \\
& retroalimentar y volver a evaluar (PBMI). \\
\hline & .. Pienso los recursos, a lo mejor me & Contexto \\
& gustaría ocupar más recursos... no los voy & evaluativo \\
& a conseguir o no van a ser adecuados para & \\
& evaluar cada alumno y yo lo quiero para & \\
& cada estudiante (PBML). & \\
\hline A veces pienso eso, reflexiono en torno a que & Tipo \\
& quizás el tipo de evaluación no fue la mejor & evaluación \\
& y el tema es que uno después de tanto & \\
\hline
\end{tabular}




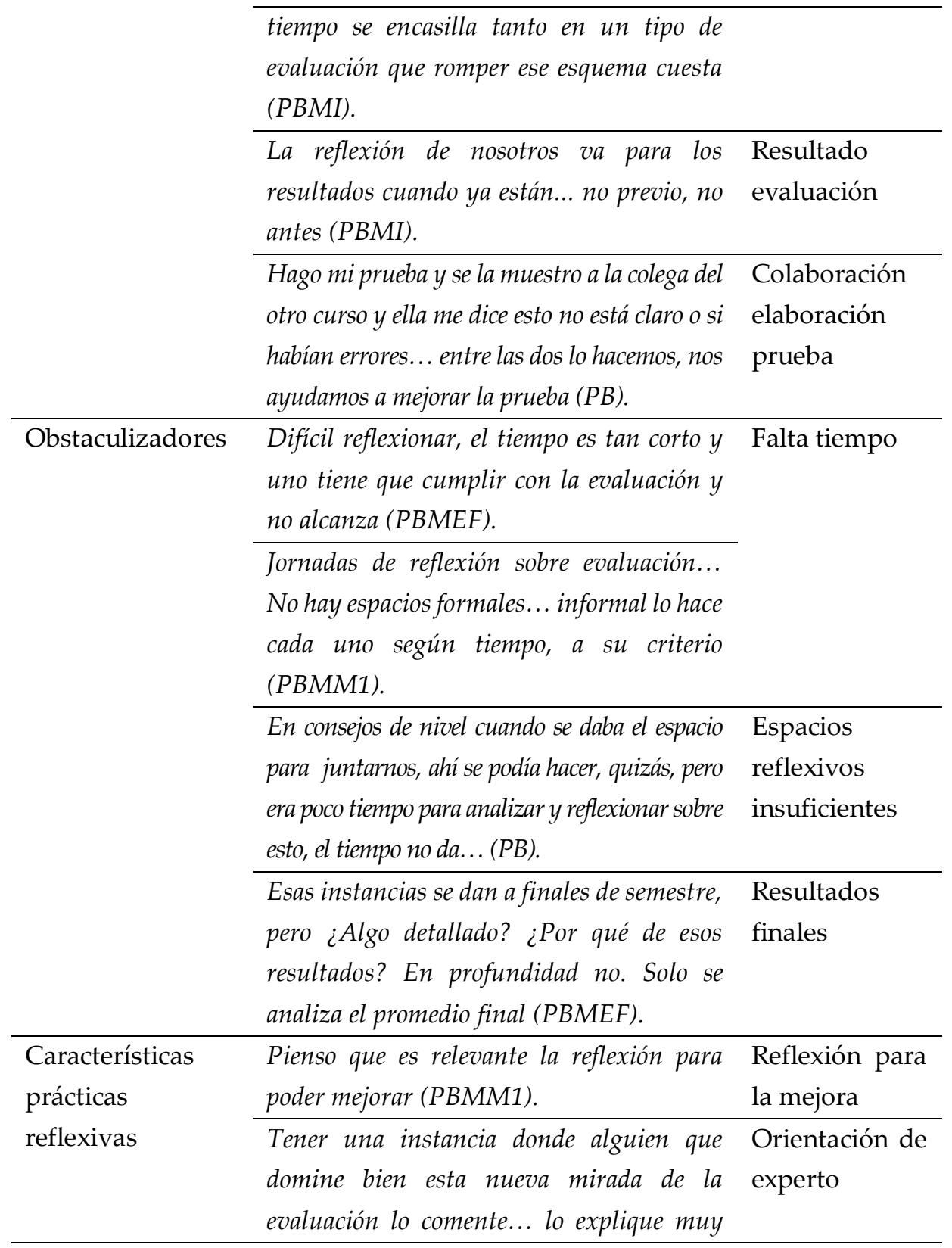




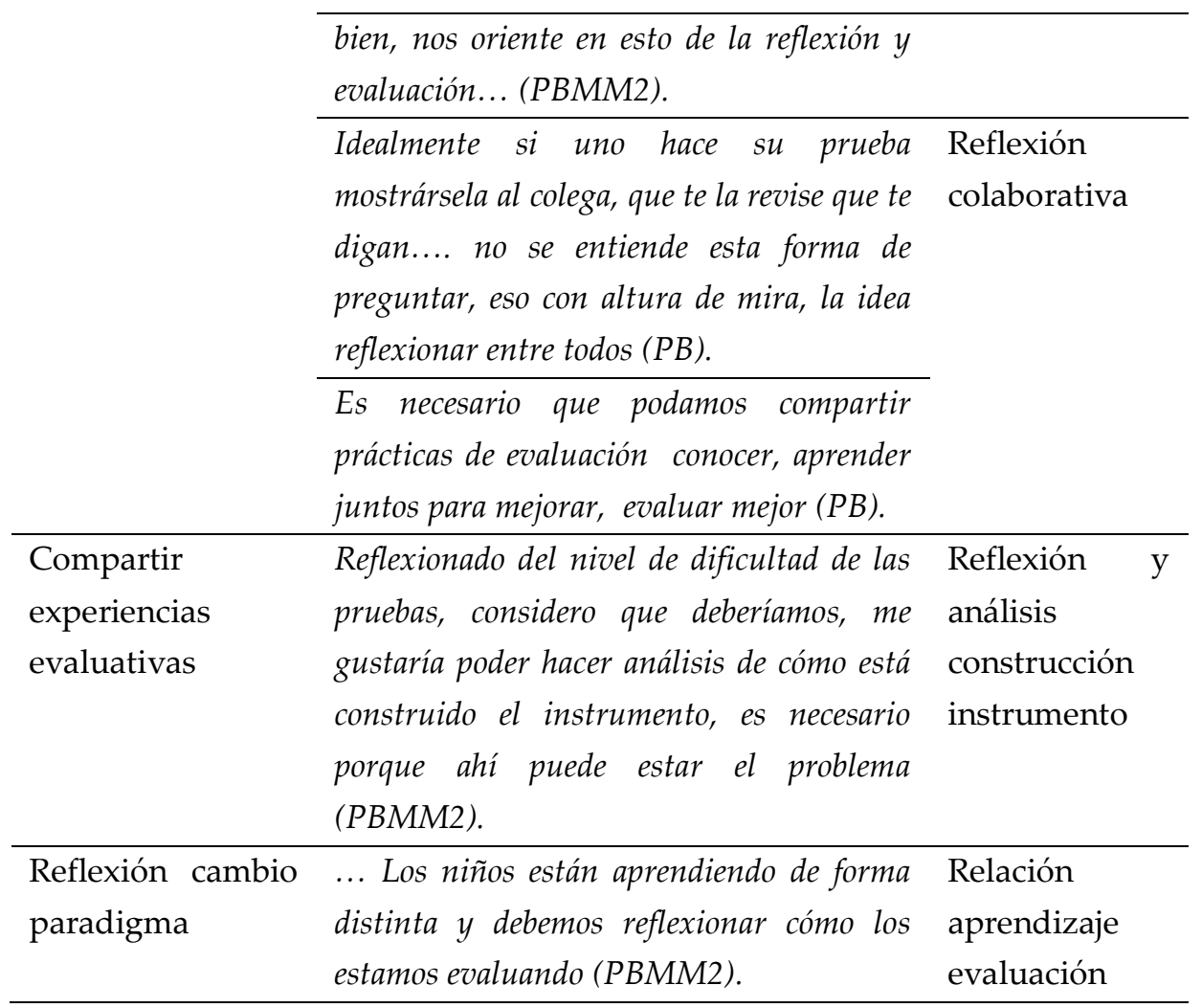

Fuente: Elaboración propia.

Tabla 7. Categoría Tipos de saberes a evaluar.

\begin{tabular}{llll} 
Sub-categoría & Cita textual & Código \\
\hline Conocer & El conocer solamente... es evaluar el & $\begin{array}{l}\text { Evalúa } \\
\text { conocimiento }\end{array}$ \\
& conocer (PBMM1). & & Aplicación \\
\hline Saber hacer & $\ldots$ que sepan manejar estrategias para & comprender mejor, que apliquen... Me contenidos \\
& enfoco siempre en las estrategias de \\
& comprensión en la aplicación de los \\
& contenidos $(P B M L)$. & \\
\hline
\end{tabular}




\begin{tabular}{|c|c|c|}
\hline \multirow[t]{2}{*}{ Ser } & $\begin{array}{l}\text { Las actitudes... en las clases sí las evalúo } \\
\text { todos los dias, que respeten sus turnos, que } \\
\text { participen de manera ordenada, que } \\
\text { manifiesten interés por la asignatura... lo } \\
\text { que voy observando de su comportamiento } \\
\text { (PBMM). }\end{array}$ & $\begin{array}{l}\text { Observación } \\
\text { actitudes }\end{array}$ \\
\hline & $\begin{array}{l}\text { También indicadores asociados a la } \\
\text { responsabilidad, esfuerzo, trabajo } \\
\text { colaborativo según los objetivos } \\
\text { trasversales, si aporto al grupo... ahí está el } \\
\text { ser dentro de la pauta. (PBMI). }\end{array}$ & $\begin{array}{l}\text { Objetivos } \\
\text { transversales }\end{array}$ \\
\hline
\end{tabular}

Fuente: Elaboración propia.

Tabla 8. Categoría Agentes de la evaluación.

\begin{tabular}{lll} 
Sub-categoría & Cita textual & Código \\
\hline Autoevaluación & Se autoevalúan y después yo trato que sea & Autoevaluación \\
& constante y los puntos en que ellos constante para \\
& contestaron que falta mejorar, ellos tratan la mejora \\
& y se motivan por mejorar. Van mejorando, \\
& cada autoevaluación van mejorando \\
& $($ PBML). & \\
\hline Coevaluación & No he realizado coevaluación, la verdad & Ausencia de \\
& nunca (PBMI). & coevaluación \\
\hline Metaevaluación & Lo que sí nos revisan la prueba UTP, que & Revisión de \\
& esté bien, que cumplamos con el formato formato \\
& $(P B M M 2)$. & instrumentos \\
\hline & No se hace, que evalúen nuestros & Ausencia \\
& instrumentos de evaluación, cómo evalúo, metaevaluación & \\
\hline & no (PBMM2).
\end{tabular}

Fuente: Elaboración propia.

174 | INTEREDU № 5 VOL. II (DiCIEMBRE 2021) PÁGs. 155-199. ISSN: 2735-6523 
Prácticas reflexivas en procesos evaluativos de profesores de enseñanza básica

Tabla 9. Categoría Momentos de la evaluación.

\begin{tabular}{|c|c|c|}
\hline \multirow[t]{2}{*}{ Inicial } & $\begin{array}{l}\text { Cuando ellos responden uno se da cuenta de } \\
\text { los conocimientos previos para poder } \\
\text { comenzar con los nuevos contenidos (PB). }\end{array}$ & $\begin{array}{l}\text { Conocimientos } \\
\text { previos }\end{array}$ \\
\hline & $\begin{array}{l}\text { Inicio de todas las clases, preguntas de qué } \\
\text { saben del tema que voy a presentar y sobre } \\
\text { todo si lo relacionan con algo que les haya } \\
\text { pasado a ellos... (PBMM2). }\end{array}$ & $\begin{array}{l}\text { Evaluación } \\
\text { inicial clase a } \\
\text { clase }\end{array}$ \\
\hline \multirow[t]{4}{*}{ Proceso } & $\begin{array}{l}\text { Hago evaluación formativa para ir } \\
\text { monitoreando lo que van aprendiendo los } \\
\text { chiquillos y para ir reforzando en los que } \\
\text { estén más débiles (PBMM1). }\end{array}$ & $\begin{array}{l}\text { Monitoreo y } \\
\text { refuerzo }\end{array}$ \\
\hline & $\begin{array}{l}\text {...en las clases yo voy mirando, } \\
\text { observándolos como van realizado las } \\
\text { actividades, los voy corrigiendo. Evalúo } \\
\text { siempre (PBMEF). }\end{array}$ & $\begin{array}{l}\text { Evaluación } \\
\text { constante }\end{array}$ \\
\hline & $\begin{array}{l}\text { Esto me permite poder ir mejorando, voy } \\
\text { viendo cómo avanzan, si aprenden y como } \\
\text { están para la evaluación final (PBMEF). }\end{array}$ & $\begin{array}{l}\text { Evaluación de } \\
\text { proceso para la } \\
\text { mejora }\end{array}$ \\
\hline & $\begin{array}{l}\text { Evaluaciones formativas, para saber } \\
\text { quiénes van avanzando y quienes se van } \\
\text { quedando atrás, ir reforzando (PB). }\end{array}$ & $\begin{array}{l}\text { Avanzar y } \\
\text { reforzar }\end{array}$ \\
\hline Final & $\begin{array}{l}\text { No hago preguntas diferentes en la } \\
\text { evaluación final de un tema. Es } \\
\text { prácticamente lo mismo que se va } \\
\text { trabajando en clases y en las evaluaciones } \\
\text { formativas (PBMM1). }\end{array}$ & $\begin{array}{l}\text { Pertinente al } \\
\text { proceso } \\
\text { enseñanza } \\
\text { aprendizaje. }\end{array}$ \\
\hline
\end{tabular}


Sí, me permite dar un cierre a un contenido Cierre proceso

$y$ poder finalmente saber si se logran los

objetivos. De manera inmediata me permite

saber si aprendió o no al final del proceso

(PBMEF).

Fuente: Elaboración propia.

Tabla 10. Categoría Procedimientos de evaluación.

\begin{tabular}{lll}
\hline Técnicas & $\begin{array}{l}\text { Prácticos, construcción de cuerpo } \\
\text { geométricos, videos explicativos... }\end{array}$ & Variedad de \\
Construcción de mándalas para ver el tema & \\
de la simetría (PBMM1). & \\
\hline Pruebas escritas y un trabajo al año... & Frecuencia \\
prueba escrita mixta, ese utilizo más, casi & evaluación \\
siempre (PBMM1). & escrita \\
\hline La pauta de cotejo, no sé, estoy como más & Pauta de cotejo \\
acostumbrada, me es más fácil y me permite & facilita \\
ir evaluando fácilmente lo que observo, va & monitoreo \\
con lo que necesito evaluar (PBMEF). & \\
\hline Porque estoy acostumbrada a eso, es más & Prueba Escrita \\
fácil la corrección y uno se va mecanizando & rápida \\
con el tiempo (PBMI). & corrección \\
\hline
\end{tabular}

Fuente: Elaboración propia.

DISCUSIÓN DE HALLAZGOS

Categoría: Propósito de la evaluación

Subcategoría: Toma de decisiones

A la luz de los hallazgos es posible señalar que los profesores declararon que las decisiones que toman, tras la evaluación, dicen relación 176 | INTEREDU № 5 VOL. II (DiCIEMBRE 2021) PÁGs. 155-199. ISSN: 2735-6523 
con identificación de debilidades de sus estudiantes focalizando la toma de decisiones para la mejora.

Me doy cuenta, veo las debilidades de los chiquillos, en que están débiles para enfrentar lo que se viene (PBMM1).

Asimismo, los participantes exponen que la toma de decisiones está orientada al refuerzo de contenidos y comprobar el avance de sus estudiantes.

Siempre tratando de reforzar contenidos que los chiquillos van a tener que utilizar para afrontar lo que sigue (PBMM1).

Los planteamientos de los docentes en respuesta al propósito de la evaluación se alinean con Martínez (2016) quien declara que las prácticas evaluativas constituyen un aspecto esencial para la generación de información como: nivel de dominio logrado por el estudiante sobre los contenidos, las capacidades desarrolladas, su potencial de rendimiento y respuesta en situaciones reales en las que deba utilizar lo aprendido. Esto permite la toma de decisiones pedagógicas que faciliten la mejora del aprendizaje, más que etiquetarlas en un nivel $u$ otro. Es decir, la evaluación como proceso de recogida, análisis e interpretación de resultados con el fin de valorarlos y que conlleve una toma de decisiones (Santos, 2014). Por tanto, la toma de decisiones es útil para elevar la calidad del proceso de enseñanza aprendizaje (Jordán et al., 2017).

Subcategoría: Logro de objetivos de aprendizajes

Para los docentes la evaluación permite verificar el nivel de logro respecto a los objetivos de aprendizajes planteados, permitiéndoles tomar decisiones respecto al refuerzo de estos objetivos. 
El objetivo de evaluar es para ver si logré los objetivos con los niños (PBMEF).

Lo que se condice por lo planteado por Brookhart (2009) quien señala que uno de los propósitos es comprobar si se han conseguido los objetivos propuestos y en qué grado. Es decir, corroborar el logro de aprendizajes en los alumnos para la toma de decisiones con foco en la mejora continua de su labor docente (Chappuis y Stiggins, 2002).

\section{Subcategoría: Retroalimentación}

Los participantes utilizan la evaluación para poder realizar el proceso de retroalimentación, siendo relevante destacar que señalan evaluar para retroalimentar en base a los errores de los estudiantes en la evaluación.

Principalmente en los errores que cometieron los chiquillos... (PBMM1).

Sin embargo, los docentes también declararon utilizar la retroalimentación después de la evaluación como un refuerzo positivo en base a los aciertos que los estudiantes han obtenido en los procesos evaluativos, permitiendo la búsqueda de mejoras que puedan evidenciarse en evaluaciones posteriores.

Refuerzo positivo siempre cuando responden bien, la mayoría de las veces pasa eso que responden bien (PBMM2).

Los docentes describen entre las prácticas de retroalimentación el refuerzo entre pares, atribuyéndole a este una importancia para la mejora en los procesos de aprendizaje. 
Oriento para que vayan respondiendo entre sí, colaborando con sus compañeros de clase, así realizo retroalimentación (PBMM1).

Dentro de las prácticas los docentes declaran realizar retroalimentación de manera continua y en base a los aciertos y errores de sus estudiantes.

Se van dando cuenta y vemos el porcentaje de aciertos y los errores que van cometiendo, entonces yo inmediatamente voy ahí retroalimentado los errores (PBMM1).

En las prácticas descritas por los docentes la retroalimentación es utilizada tras todos los procesos evaluativos siendo un elemento central de la evaluación. Por consiguiente, sin retroalimentación no existe evaluación, pues la mejora del desempeño del estudiante dependería de ella (Martínez, 2016). Los docentes declararon que realizan distintas instancias de retroalimentación, pero se evidencia que el foco está en el refuerzo positivo entre pares, considerando que el proceso de retroalimentación efectiva no debe darse solo del docente al estudiante, sino que también de distintas formas: entre compañeros, como auto retroalimentación o la retroalimentación brindada por el estudiante al docente (Clarke, 2014).

Categoría: Reflexión práctica docente

Subcategoría: Reflexión práctica evaluativa

Los docentes de manera individual realizan reflexión de sus prácticas evaluativas en base a la construcción de instrumentos de evaluación, focalizando esta reflexión en los aspectos como la selección de preguntas validadas, redacción y ortografía. 
Preocuparme que este bien hecho, bien elaborada la pregunta, que no tenga distractores... que sea un instrumento efectivo... (PBMM1).

Tras las declaraciones de los docentes se rescata que la elaboración de los instrumentos es uno de los componentes evaluativos sobre los cuales realizan reflexión, lo cual es importante considerando que los instrumentos dependen del sentido y la forma que se le dé a la evaluación (Rodríguez e Ibarra, 2011). Esta construcción, en ocasiones, la validan con la ayuda de sus pares, lo cual permite mejorar el instrumento antes de ser aplicado los estudiantes.

Hago mi prueba y se la muestro a la colega del otro curso y ella me dice, esto no está claro o si había errores... entre las dos lo hacemos, nos ayudamos a mejorar la prueba (PBMM1).

Previo a la elaboración de los instrumentos, según lo declarado en las entrevistas, los docentes reflexionan en torno a las características de los estudiantes.

Busco la mejor manera de evaluarlos en base a sus características... (PBMEF).

Otra práctica que es posible extraer de las declaraciones de los docentes es el análisis de las condiciones propicias para llevar a cabo la evaluación de aprendizajes a sus estudiantes.

... Pienso los recursos, a lo mejor me gustaría ocupar más recursos... no los voy a conseguir o no van a ser adecuados para evaluar cada alumno $y$ yo lo quiero para cada estudiante (PBML). 
Reflexionando también sobre la pertinencia del tipo de evaluación aplicada en contraste con lo planteado por Costamagna (2008), para quien la evaluación no es un momento final del proceso en el que se comprueba cuáles han sido los resultados del trabajo, es un permanente proceso reflexivo apoyado en evidencias de diverso tipo.

La reflexión de nosotros va para los resultados cuando ya están...no previo, no antes. (PBMI).

Los docentes declaran la participación de los estudiantes en los procesos evaluativos como una práctica necesaria de incorporar. Sin embargo, declaran no incorporar esta práctica.

Por ejemplo, les planteo a los chiquillos si prefieren hacer la evaluación en una prueba escrita o una presentación... (PBMI).

Se extrae de las entrevistas que los docentes de manera autónoma buscan instancias para reflexionar cuando se obtiene malos resultados, esto con el objetivo de volver a evaluar. El Mineduc (2018) declara que es preciso que los profesores consideren los resultados de la evaluación como una fuente relevante de información para reorientar y transformar sus prácticas en busca de mejoras en los resultados de aprendizaje de los estudiantes.

Las instancias las hace uno, por ejemplo, me va mal en una evaluación con un grupo, ahí lo comentó con profesora jefe, con coordinadora, UTP, para replantear, retroalimentar y volver a evaluar (PBMI).

\section{Subcategoría: Obstaculizadores}

Existen ciertas condicionantes que dificultan la reflexión de las prácticas evaluativas de los participantes. Dentro de estas destacan la falta de tiempo para reflexionar en función de la evaluación como lo plantean INTEREDU № 5 VOL. II (DicIEMBRE 2021) PÁGs.155-199. ISSN: 2735-6523| 181 
Anijovich y Capelletti (2018). Los docentes2 buscan mejorar sus prácticas evaluativas, pero no siempre reciben la orientación y/o capacitaciones para ello (Hernández-Nodarse, 2017). Los docentes develan que entre los factores que dificultan el proceso de reflexión está la manera en que se organiza el trabajo del docente, lo cual no permite abrir instancias colectivas de análisis y reflexión.

En los consejos de nivel cuando se daba el espacio para juntarnos, ahí se podía hacer quizás, pero era poco tiempo para analizar y reflexionar sobre esto, el tiempo no da... (PB).

Sin dejar de lado la falta de tiempo.

Difícil reflexionar, el tiempo es como tan corto y uno tiene que cumplir con la evaluación y no alcanza (PBMEF).

Sumado a la falta de tiempo, los espacios reflexivos en la institución son insuficientes y no se ajustan a los procesos reflexivos, limitándose a capacitaciones metodológicas, no logrando profundizar en aspectos fundamentales de la evaluación (Hernández et al., 2018).

De manera informal, puede ser, en ciertas conversaciones con un par... pero nada planificado (PBML).

Además, es posible vislumbrar que la reflexión que realizan es informal y de manera personal como también con pares cercanos. No existe el profesor irreflexivo. Si bien es cierto lo que plantea Sanmartí (2007) que la práctica reflexiva es responsabilidad individual, también es necesario que dentro del ámbito de la gestión se den los espacios para que esta se pueda desarrollar de manera colectiva, cooperativa y planificada. 
Jornadas de reflexión sobre evaluación... No hay espacios formales... informal lo hace cada uno según tiempo, a su criterio (PBMM1).

Los espacios formales en los cuales se pueden dar instancias reflexivas en el establecimiento se realizan principalmente a fin de semestre $\mathrm{y}$ estos son focalizados principalmente en la exposición y análisis de resultados finales por curso y prueba SIMCE. Torres et al., (2020) señalan que los establecimientos no favorecen los procesos de reflexión porque no existen espacios dispuestos para esto, estiman que los Consejos Técnicos propiciarían el análisis de las prácticas de evaluación de aprendizajes a partir del trabajo reflexivo colaborativo.

Esas instancias se dan a finales de semestre, pero ¿Algo detallado? ¿Por quéde esos resultados? En profundidad no. Solo se analiza el promedio final (PBMEF).

Los hallazgos presentados se relacionan directamente con los antecedentes expuestos en la literatura, donde destacan entre los factores que dificultan el proceso de reflexión la manera en que se organiza el trabajo del docente, lo cual no permite abrir instancias colectivas de análisis y reflexión, sin dejar de lado la falta de tiempo para el trabajo (Anijovich y Capelletti, 2018). Sumado además a la idea que los docentes no han tenido la oportunidad de problematizar colectivamente el campo de la evaluación y dejan la construcción de modelos evaluativos solo a cargo de su experiencia individual (Giovanniello, 2017).

Subcategoría: Características prácticas evaluativas reflexivas

Dentro de las descripciones de sus prácticas evaluativas los docentes entrevistados dejan ver cuáles son las características que deben tener las prácticas de reflexión sobre los procesos evaluativos frente a lo INTEREDU № 5 Vol. II (DiCIEMBRE 2021) PÁGs.155-199. ISSN: 2735-6523| 183 
cual todos coinciden en la necesidad de la reflexión para la mejora de la evaluación. Idea que se reafirma con los planteamientos de Schön (1992), quien señala, que la reflexión reconfigura el marco de actuación de los profesores y además, mejora su práctica docente.

Pienso que es relevante la reflexión para poder mejorar (PBMM1).

Consideran dentro de las características necesarias de reflexión la colaboración entre pares, como también la orientación de expertos para poder llevar a cabo estos procesos reflexivos. Esta idea también fue planteada por Eraut (2000), quien señala que la mayor parte del aprendizaje en el lugar de trabajo es aprendizaje informal logrado por la consulta y colaboración dentro del grupo de trabajo. También hace la salvedad que el apoyo y la retroalimentación son de importancia crítica para el aprendizaje, la retención y el compromiso de los profesionales, siendo esta retroalimentación más efectiva cuando la práctica reflexiva es guiada por un profesional idóneo dentro de la propia institución escolar.

Idealmente si uno hace su prueba mostrársela al colega, que te la revise, que te digan.... no se entiende esta forma de preguntar, eso con altura de mira, la idea reflexionar entre todos (PB).

Estas instancias de reflexión colaborativa y orientadas por expertos, según los docentes, son necesarias junto con la implementación de instancias en donde el profesorado pueda compartir experiencias evaluativas y de reflexión en torno a la construcción de instrumentos.

Es necesario que podamos compartir prácticas de evaluación, conocer, aprender juntos para mejorar, evaluar mejor (PB). 
Para los docentes es necesaria la reflexión en torno al cambio de paradigma de la evaluación, poniendo el foco en la relación aprendizajeevaluación. Concordante con esto, el Mineduc ha estado orientando mediante diversos instrumentos la reflexión sobre las prácticas de evaluación del profesorado en el aula, asumiendo que esta debe estar relacionada con el objetivo educativo de la mejora de los aprendizajes (Vargas, 1998).

Se deberían dar las instancias para reflexionar, cambiar la visión de la evaluación, necesitamos este cambio de paradigma... (PBMM2).

Categoría: Tipo de saberes a evaluar

Subcategoría: Conocer

Queda en evidencia que los docentes evalúan el conocer en base a los contenidos de la asignatura, utilizando principalmente la prueba escrita. Esto coincide con lo señalado por Fernández (2014), quien declara que cuando se pregunta a los profesores qué aprendizajes evalúan, la respuesta más generalizada refiere a los conocimientos adquiridos en relación a la materia, esto centrado más en el dominio de los instrumentos para el saber, centralmente la atención, memoria y pensamiento (Delors, 1996).

El conocer solamente... es evaluar el conocer (PBMM1).

\section{Subcategoría: Saber hacer}

Es posible evidenciar que la evaluación del saber hacer se realiza en actividades de aplicación, donde los estudiantes utilizan estrategias para evidenciar sus aprendizajes a través de la ejecución. Fernández (2014) plantea que los sujetos aprenden o deberían aprender más cosas, tales como procedimientos y destrezas intelectuales para utilizar y aplicar estos conocimientos. 
...que sepan manejar estrategias para comprender mejor, que apliquen... Me enfoco siempre en las estrategias de comprensión, en la aplicación de los contenidos (PBML).

\section{Subcategoría: Ser}

De acuerdo a lo declarado, los docentes evalúan el ser de manera transversal, en base a la observación de las actitudes de los estudiantes y dando respuesta a los objetivos transversales. Le dan importancia a este aprendizaje tal como lo plantea Fernández (2014), ya que los sujetos deberían aprender a desarrollar un determinado tipo de actitudes, intereses y afectos en relación a determinados objetivos y situaciones. Es decir, no sólo desarrollar determinados hábitos intelectuales, sino también comportamientos sociales.

Las actitudes... en las clases sí las evalúo todos los días, que respeten sus turnos, que participen de manera ordenada, que manifiesten interés por la asignatura... lo que voy observando de su comportamiento (PBMM).

Categoría: Agentes de la evaluación

\section{Subcategoría: Autoevaluación}

Los hallazgos referentes a la autoevaluación arrojan que no todos los docentes utilizan la autoevaluación y los que la utilizan la realizan a través de los procesos formativos y de manera constante para la mejora. Esto puede tomar tiempo y requiere práctica sistemática y no ser de manera aislada en el tiempo (Moreno, 2016).

...tenían que marcar si tomaban apuntes, si estudiaban del cuaderno, si hacían preguntas a la profesora, cosas así, pero ufff fue hace mucho tiempo, ahora no lo hago (PBMM1). 
Ellos se autoevalúan y después yo trato que sea constante y los puntos en que ellos contestaron que falta mejorar, ellos tratan y se motivan por mejorar. Van mejorando cada autoevaluación (PBML).

\section{Subcategoría: Coevaluación}

Los participantes no utilizan la coevaluación dentro de sus prácticas evaluativas, destacando solo un docente que la realizaba de manera presencial, quien tras el contexto de pandemia y clases online dejó de realizarla, a pesar de ser valiosa al poner el trabajo en manos de los alumnos. Así, el profesor puede estar libre para observar y reflexionar sobre lo que está sucediendo, para destacar las intervenciones (Martínez, 2016). Al hacer distintas contribuciones al desarrollo del aprendizaje de los alumnos, estos consiguen objetivos que no pueden alcanzarse de ninguna otra manera (Casanova, 2007).

No he realizado coevaluación, la verdad nunca (PBMI).

\section{Subcategoría: Metaevaluación}

En el proceso reflexivo la metaevaluación es clave. Tras la consulta en la entrevista de la utilización de la metaevaluación, los docentes declararon que como evaluación de la evaluación no se realiza y que lo más cercano es lo realizado desde UTP que se remite a la revisión de aspectos formales de los instrumentos de evaluación.

Lo que, si nos revisan la prueba UTP, que esté bien, que cumplamos con el formato (PBMM2).

No se realiza la incorporación en la práctica de reflexión respecto a la calidad de la propia evaluación efectuada, es decir, la evaluación de la evaluación. La cual, bien realizada, se puede convertir en una estrategia INTEREDU № 5 Vol. II (DiCIEMBRE 2021) PÁGs.155-199. ISSN: 2735-6523| 187 
para la toma de decisiones con foco en la cimentación de una cultura de autorreflexión (Marcipar y Luciani 1974).

No se hace, que evalúen nuestros instrumentos de evaluación, cómo evalúo, no (PBMM2).

Categoría: momentos de la evaluación

Subcategoría: Evaluación inicial

Los docentes participantes describen que la utilizan para recoger información sobre los conocimientos previos. Como lo plantean Castillo y Cabrerizo (2010), la evaluación inicial se utiliza para recoger datos de la situación de partida para que el proceso educativo comience con un conocimiento real de las características de los alumnos. Esto además se reafirma con lo planteado por Pimienta (2008), quien señala que es esencial para recoger información del conocimiento previo de los estudiantes, necesario para adecuar la enseñanza a sus condiciones de aprendizaje.

Cuando ellos responden uno se da cuenta de los conocimientos previos para poder comenzar con los nuevos contenidos (PB).

En el discurso se evidencia que la evaluación inicial no la utilizan solo como un diagnóstico a comienzo de año o al inicio de una unidad, sino que la utilizan clase a clase, ya que permite analizar la situación del estudiante antes dar inicio del proceso y tomar decisiones según las necesidades detectadas (Sanmartí, 2007).

Inicio de todas las clases, preguntas de qué saben del tema que voy a presentar y sobre todo si lo relacionan con algo que les haya pasado a ellos... (PBMM2). 
Los resultados permiten al docente, según lo declarado en las entrevistas, revisar la planificación y realizar los ajustes necesarios a la realidad del grupo. Esto se condice con lo señalado por Sanmartí (2007), quien plantea que esta evaluación permite al docente comprobar el grado de alcance de objetivos previos necesarios para lograr los nuevos objetivos. Además, debe tener un carácter diagnóstico que permita tomar decisiones pertinentes para orientar el proceso antes de su inicio, adecuando la enseñanza a sus condiciones de aprendizaje (Santos, 2014).

Esta evaluación me da al tiro la visión de cómo está cada uno de los estudiantes para de esta manera adecuar el trabajo con cada uno y poder ajustar la planificación a la realidad del curso (PBMEF).

\section{Subcategoría: Evaluación de proceso}

Utilizan la evaluación de procesos de manera constante o de carácter continuo, principalmente a través de procedimientos informales, pues la dinámica habitual de una clase hace inviable una aplicación constante de instrumentos o pruebas formales (Moreno, 2016).

...en las clases yo voy mirando, observándolos como van realizando las actividades, los voy corrigiendo, evalúo siempre (PBMEF).

Las prácticas asociadas a esta evaluación las describen como monitoreo y refuerzo. En relación a esta idea, Fernández (2014) plantea que la finalidad de la evaluación de proceso es informar a los alumnos de sus aciertos, errores o lagunas; es decir, son participantes junto al docente, comparten metas de aprendizaje y comprenden cómo van progresando (Moreno, 2016).

Hago evaluación formativa para ir monitoreando lo que van aprendiendo los chiquillos y para ir reforzando en los que estén más débiles (PBMM1). INTEREDU № 5 Vol. II (DiCIEMBRE 2021) PÁGS.155-199. ISSN: 2735-6523| 189 
También la utilizan para verificar los aprendizajes de sus estudiantes. Siendo esto muy enriquecedor para el profesor, sobre todo cuando analiza los resultados a nivel de grupo y observa los puntos de dificultad tanto respecto al contenido como a los procesos mentales implicados (Fernández, 2014).

En la evaluación de proceso, ahí verifico realmente si es que aprendieron o no y en la final después, en general obtengo buenos resultados (PBML).

En relación a los resultados que arroja la evaluación de proceso, los docentes toman decisiones en base a ir avanzando o reforzando los contenidos. Así lo señala Casanova (2007) quien plantea que la rigurosidad de esta evaluación conlleva a mejorar el proceso de enseñanza, ya que favorece la recogida sistemática de información. Esto permite la toma de decisiones inmediatas para la resolución de las dificultades que van presentando los estudiantes. Por tanto, se emplea para detectar el problema de aprendizaje que se presenta, resolviendo mediante la adecuación de las actividades y explicaciones oportunas.

Evaluaciones formativas, para saber quiénes van avanzando, y a quienes se van quedando atrás ir reforzando (PB).

Le atribuyen a la evaluación de proceso el poder ir mejorando. Como lo argumenta Fernández (2014), de esta modalidad de evaluación se desprenden decisiones de mejora que afectan a todos los elementos que intervienen en el proceso educativo.

Esto me permite poder ir mejorando, voy viendo cómo avanzan, si aprenden y cómo están para la evaluación final (PBMEF). 


\section{Subcategoría: Evaluación final}

Frente a la evaluación final describen que la aplican para dar cierre a un proceso del aprendizaje. Se realiza al terminar el proceso de enseñanza y aprendizaje, aunque éste sea parcial (Castro et al., 2006). En esta evaluación se comprueban los resultados obtenidos, aunque no por ello debe tener funcionalidad sumativa o exclusivamente teniendo como propósito determinar niveles de rendimiento. Posee un carácter retrospectivo, sanciona lo que ha ocurrido, viéndolo desde el proceso final (Gimeno 1997).

Sí, me permite dar un cierre a un contenido y poder finalmente saber si se logran los objetivos. De manera inmediata me permite saber si aprendió o no al final del proceso (PBMEF).

Los docentes enfatizan en sus declaraciones la relevancia de la relación y pertinencia entre el proceso de aprendizaje y la evaluación final, siendo fundamental el conocimiento previo del sistema de evaluación como uno de los aspectos importantes para que en los estudiantes repercuta de forma significativa en sus vivencias en relación con la evaluación. Ello, favoreciendo su autocontrol, optimización de sus actitudes hacia las pruebas de evaluación y, por tanto, ayudando también a la mejora de su aprendizaje.

No hago preguntas diferentes en la evaluación final de un tema. Es prácticamente lo mismo que se va trabajando en clases y en las evaluaciones formativas (PBMM1). 
Categoría: Procedimientos evaluación

Subcategoría: Técnicas

Los procedimientos de evaluación los centran en las técnicas utilizadas para evaluar, enumerando variedad de instrumentos, siendo esto respaldado como uno de los principios básicos de evaluación. Los docentes deben aplicar variadas técnicas evaluativas, dando respuesta a la diversidad. Siendo por esencia la plural o multidimensional, implicando la necesidad de ampliar el repertorio de procedimientos, técnicas e instrumentos tradicionalmente utilizados (Rodríguez e Ibarra, 2011).

Prácticos, construcción de cuerpo geométricos, videos explicativos... Construcción de mándalas para ver el tema de la simetría (PBMM1).

A pesar de la variedad de instrumentos utilizados en sus prácticas evaluativas, estas no son permanentes, declarando los docentes el uso de instrumentos tradicionales, cuantitativos y repetitivos, coherente con lo planteado por Rodríguez e Ibarra, (2011).

Pruebas escritas y un trabajo al año... prueba escrita mixta, ese utilizo más, casi siempre (PBMM1).

Atribuyen la frecuencia en la utilización de la prueba escrita porque les permite optimizar el tiempo.

Porque estoy acostumbrada a eso, es más fácil la corrección y uno se va mecanizando con el tiempo (PBMI).

Al momento de evaluar a través de la observación, declaran utilizar la pauta de cotejo que facilita el monitoreo. Para que la realización de las 
observaciones sea efectiva, son necesarios instrumentos como listas de cotejo, escalas estimativas, rúbricas, entre otras (Pimienta, 2008).

La pauta de cotejo, no sé, estoy como más acostumbrada, me es más fácil y me permite ir evaluando fácilmente lo que observo, va con lo que necesito evaluar (PBMEF).

\section{CONCLUSIONES}

A la luz de los resultados se puede establecer variadas conclusiones. En base al objetivo relacionado con caracterizar los aspectos que favorecen o dificultan las prácticas reflexivas en evaluación, se revela que los docentes no tienen instancias formales para llevar a cabo prácticas reflexivas. Asimismo, el factor tiempo impide que puedan realizar mayores análisis relacionados a sus prácticas evaluativas. Se presenta como otro obstaculizador el hecho que las instancias formales de reunión del cuerpo docente y equipo técnico se focalizan en exposición de resultados académicos y/o de pruebas estandarizadas como el SIMCE, sin espacios para el análisis y la reflexión colectiva.

Por otro lado, el análisis de contenido ha permitido evidenciar como factores que favorecen la reflexión el hecho que los docentes consideran fundamental la reflexión para la mejora de las prácticas evaluativas y, por ende, del aprendizaje. Siendo para este grupo de docentes una característica necesaria de la reflexión el carácter colaborativo de esta y la orientación de un experto que les guíe en los procesos reflexivos. Desde aquí nace la necesidad de generar espacios reflexivos.

En función del objetivo relacionado con identificar los componentes evaluativos sobre los cuales los profesores realizan prácticas reflexivas, se concluye que los docentes realizan de manera autónoma procesos reflexivos sobre distintos aspectos de la evaluación con foco en 
construcción y análisis de instrumentos evaluativos y resultados de aprendizaje. En otros aspectos de la evaluación, se evidencia en sus relatos que realizan reflexión sobre sus prácticas evaluativas al momento de planificar las evaluaciones, analizando los recursos adecuados y el contexto evaluativo al que se enfrentaron los estudiantes. Luego de la apreciación de los resultados de aprendizaje, los docentes reflexionan en cuanto a la pertinencia de la estrategia y el tipo de evaluación.

En cuanto al objetivo general de esta investigación, se logra establecer que los aspectos que determinan las prácticas reflexivas en los procesos evaluativos desarrollados por profesores de educación primaria son los espacios y tiempos destinados para los procesos reflexivos, donde los docentes realizan estas prácticas de manera autónoma. También se hace evidente la necesidad de planificar y sistematizar la reflexión para mejorar las prácticas evaluativas.

Se podría inferir a partir de lo anterior, que cualquier intento por mejorar los aprendizajes que ignore la importancia e impacto de estos aspectos implícitos en las prácticas evaluativas puede ver reducido sus efectos si los profesores no tienen conciencia y los espacios necesarios para realizar procesos de reflexión. Es importante, en consecuencia, tomar conciencia respecto de la importancia de reflexionar críticamente sobre las prácticas evaluativas, para que desde ahí la evaluación cumpla con su finalidad y contribuya al aprendizaje.

Como proyección de este estudio, se puede investigar sobre cómo los profesores determinan sus instrumentos de evaluación, cómo reflexionan en la relación a su pertinencia durante el proceso de enseñanza aprendizaje, dado que los profesores planifican la evaluación -instrumentos propiamente tal- al finalizar una unidad y no lo desarrollan desde un comienzo. Además, se deberían generar instancias de capacitación a los docentes para instalar una cultura de reflexión, tanto 194 | INTEREDU № 5 VoL. II (DiCIEMBRE 2021) PÁGs. 155-199. ISSN: 2735-6523 
de la evaluación de aprendizajes como de otros aspectos propios del proceso de enseñanza aprendizaje.

\begin{abstract}
Mención: Este trabajo surge de la tesis realizada por la autora principal para optar al grado de Magíster en ciencias de la Educación de la Universidad Católica de la Santísima Concepción, Chile, con su profesora directora de tesis como autora de correspondencia.
\end{abstract}

\title{
REFERENCIAS BIBLIOGRÁFICAS
}

Anijovich, R. y Capellett, G. (2018). La práctica reflexiva en los docentes en servicio. Posibilidades y limitaciones. Espacios en Blanco. Revista de Educación, (28), 75-90.

Ahumada, P. (2001). La evaluación en una concepción de aprendizaje significativo. Ediciones Universitarias de Valparaíso, Pontificia Universidad Católica de Valparaíso.

Álvarez-Gayou, J. (2014). Cómo hacer investigación cualitativa. Fundamentos y metodología. Paidós.

Araneda, A., Parada, M. y Vásquez, A. (2008). Investigación cualitativa en educación y pedagogía. Ediciones Universidad Católica de la Santísima Concepción.

Ballestín, B. y Fábregues, S. (2018). La práctica de la investigación cualitativa en ciencias sociales y de la educación. Editorial UOC.

Bisquerra, R., Dorio, I., Gómez, J., Latorre, A., Martínez, F., Massot, I., y Vila, R. (2014). Metodología de la investigación educativa. La Muralla.

Brookhart, S. (2009). Editorial. Educational Measurement. Issues and Practice, 28(1), 1-2. https://doi.org/10.1111/j.1745-3992.2009.01131.x 
Buendía, L., Colés, P. y Hernández, F. (1998). Métodos de investigación en psicopedagogía. McGraw-Hill.

Carr, W. y Kemmis, S. (1988). Teoría crítica de la enseñanza. Martínez Roca.

Casanova, M. (2007). Manual de evaluación educativa (9aㅡㄹ. Ed.). La Muralla.

Castillo, S. y Cabrerizo, J. (2010). Evaluación educativa de aprendizajes y competencias. Pearson Educación S.A.

Castro, F., Correa, M. y Lira, H. (2006). Curriculum y evaluación educacional [Tesis de Grado, Universidad del Bío-Bío]. Repositorio Institucional de la Universidad del Bío-Bío. http://repobib.ubiobio.cl/jspui/bitstream/123456789/1869/1/Toledo_Tapia_ Nuria.pdf

Chappuis, S. y Stiggins, R. J. (2002). Classroom assessment forlearning. Educational Leadership, 60(1), 40.

Clarke, S. (2014). Outstanding Formative Assessment: Culture and Practice. Hodder Education.

Costamagna, M. (2008). Las prácticas de evaluación de un grupo de profesores de ciencias naturales. Aula Universitaria, 1(10), 65-74.

Delors, J. (1996). Los cuatro pilares de la educación en la educación encierran un tesoro. Informe a la UNESCO de la Comisión internacional sobre la educación para el siglo XXI. Santillana/UNESCO.

Dewey, J. (1998). Cómo pensamos. Nueva exposición de la relación entre el pensamiento reflexivo y proceso educativo. Paidós.

Domingo, A. y Gómez, V. (2014). La Práctica Reflexiva. Bases, modelos e instrumentos. Narcea.

Eraut, M. (2000). Non-formal learning and tacit knowledge in professional work. British Journal of Educational Psychology, 70(1), 113-136.

Fernández, A. (2014). La evaluación de los aprendizajes en la universidad: Nuevos enfoques. Instituto de Ciencias de la Educación. Universidad Politécnica de Valencia.

196 | INTEREDU № 5 VoL. II (DiCIEMBRE 2021) PÁGs. 155-199. ISSN: 2735-6523 
Fuster, D. (2019). Investigación cualitativa: Método fenomenológico hermenéutico. Propósitos y Representaciones, 7(1), 201229. https://dx.doi.org/10.20511/pyr2019.v7n1.267

Gallardo, K., Gil, M., Contreras, B., García, E., Lázaro, R. y Ocaña, L. (2012). Toma de decisiones para la evaluación formativa: El proceso de planeación y determinación de sus mecanismos. Sinéctica, (39), 01-19.

Gimeno, J. (1997). La pedagogía por objetivos. Morata.

Giovanniello, M. (2017). Reflexiones sobre las prácticas evaluativas de Matemática en el Liceo e interrogantes para iniciar su problematización. Hilvanando experiencias, 1(2), 24-32.

Hernández, R., Fernández, C. y Baptista, M. (2014). Metodología de la investigación. McGraw-Hill.

Hernández, M., M. Gregori y D. Tomalá (2018). ¿Cómo puede transformarse verdaderamente la evaluación del aprendizaje practicada por los profesores? Una experiencia pedagógica por la mejora del profesorado. Revista Ciencias Pedagógicas en Educación, 6(1), 88-106. https://incyt.upse.edu.ec/pedagogia/revistas/index.php/rcpi/article /view/221/259

Hernández-Nodarse, M. (2017). Why Has It Been So Difficult to Transform Evaluation Practices of Learning in the Educational Context? A Critical Essay on a Pedagogical Pathology Still to Be Treated. Revista Electrónica Educare, 21(1), 1-27. https://doi.org/10.15359/ree.21-1.21

Jordán, Y., Morán, B. y Camacho, T. (2017). La evaluación de los aprendizajes y su influencia en la calidad de los procesos de enseñanza aprendizaje en el contexto universitario. Opuntia Brava, 9(1),1-10. http://opuntiabrava.ult.edu.cu/index.php/opuntiabrava/article/view/13 $4 / 130$ 
Marcipar, S. y Luciani, M. (2017): La Meta-evaluación en la agenda de la Educación Superior. Ciencias Económicas, 1(14), 185-197.

Martínez, L. (2016). Más allá de la calificación. Instrumentos para evaluar el aprendizaje. Unidad de Investigación y Desarrollo Docente, Universidad de Concepción.

Ministerio de Educación de Chile (2018). Orientaciones para la implementación del Decreto 67/2018 de evaluación, calificación y promoción escolar. Unidad de Currículum y Evaluación. https://curriculumnacional.Mineduc.cl/614/articles89350_archivo_01.pdf

Ministerio de Educación de Chile (2008). Marco para la Buena Enseñanza. https://www.docentemas.cl/docs/MBE2008.pdf

Ministerio de Educación de Chile (2020). Resultados Nacionales Evaluación Docente 2019. https://www.cpeip.cl/resultados-evaluacion-docente-2019/

Moreno, T. (2016). Evaluación del aprendizaje y para el aprendizaje. Editorial Casa Abierta al Tiempo.

Muñoz, J., Villagra, C. y Sepúlveda, S. (2016). Proceso de reflexión docente para mejorar las prácticas de evaluación de aprendizaje en el contexto de la educación para jóvenes y adultos. Revista Folios, (44), 77-91. http://www.scielo.org.co/scielo.php?pid=S0123$48702016000200005 \&$ script=sci_abstract\&tlng=es

Neiman, G. y Quaranta, G. (2006). Los estudios de casos en la investigación sociológica. En I. Vasilachis (Coord.) Estrategias de investigación cualitativa (pp. 213-237). Gedisa.

Pérez, G. (2008). Investigación cualitativa: retos e interrogantes. I. Métodos. La Muralla.

Pérez, G. (2011). Investigación cualitativa: retos e interrogantes. II. Técnicas y análisis de datos. La Muralla.

Pimienta, J. (2008). Evaluación de los aprendizajes. Pearson Prentice Hall. 198 | INTEREDU № 5 Vol. II (DiCIEMBRE 2021) PÁGs. 155-199. ISSN: 2735-6523 
Rodríguez, G. e Ibarra, S. (2011). Evaluación orientada al e-Aprendizaje estratégico. Narcea.

Rodríguez, M. (2019). Reflexión sobre las prácticas educativas que realizan los docentes universitarios: El caso de la Facultad de Educación de UNIMINUTO. Formación universitaria, 12(1), 109120. https://dx.doi.org/10.4067/S0718-50062019000100109

Ruiz, J. (2003). Metodología de la investigación cualitativa. Universidad de Deusto.

Santos, M. (2014). La evaluación como aprendizaje cuando la flecha impacta en la diana. NARCEA, S.A.

Schön, D. (1992). La formación de profesionales reflexivos. Hacia un nuevo diseño de la enseñanza y el aprendizaje en las profesiones. Paidós.

Sanmartí, N. (2007). 10 ideas clave. Evaluar para aprender. Graó.

Torres, P. (2017). Evaluación educativa como oportunidad para la reflexión acerca de la práctica pedagógica. MULTICIENCIAS, 17(1), 44-50.

https://produccioncientificaluz.org/index.php/multiciencias/article /view/23602/23909

Torres, M., Yépez, D. y Lara, A. (2020). La reflexión de la práctica docente. Revista de ciencias sociales y humanidades Charkiñan, (10), 87-101. https://chakinan.unach.edu.ec/index.php/chakinan/article/view/31 $6 / 308$

Vargas, C. (1998). Evaluación para aprender: Hacia una evaluación participativa en la escuela básica. Ministerio de Educación de Chile.

Vasilachis, I. (2004). Estrategias de investigación cualitativa. Gedisa.

Yurén, T., Navia, C. y Saenger, C. (2005). Ethos y autoformación del docente. Análisis de dispositivos de formación de profesores. Ediciones Pomare. 